\title{
HUBUNGAN OBESITAS DENGAN TERJADINYA GANGGUAN PENDENGARAN SENSORINEURAL
}

\author{
${ }^{1}$ Rahmi Sibagariang \\ ${ }^{2}$ Muhammad Edy Syahputra Nasution \\ ${ }^{2}$ Siti Masliana Siregar \\ ${ }^{3}$ Isra Thristy
}

\begin{abstract}
${ }^{1}$ Fakultas Kedokteran, Universitas Muhammadiyah Sumatera Utara
${ }^{2}$ Bagian Ilmu Penyakit Telinga, Hidung, dan Tenggorokan, Fakultas Kedokteran, Universitas Muhammadiyah Sumatera Utara

${ }^{3}$ Departemen Histologi, Fakultas Kedokteran, Universitas Muhammadiyah Sumatera Utara
\end{abstract}

\section{Alamat Korespondensi:}

Muhammad Edy Syahputra Nasution

Bagian Ilmu Penyakit Telinga, Hidung, dan Tenggorokan, Fakultas Kedokteran Universitas Muhammadiyah Sumatera Utara, Medan, 2020

+62821-6782-1319

Email: mhd.edysyahputra@umsu.ac.id 


\begin{abstract}
ABSTRAK
Obesitas merupakan peningkatan total lemak tubuh, yaitu apabila ditemukan kelebihan berat badan $>20 \%$ pada pria dan $25 \%$ pada wanita karena lemak. Meningkatnya obesitas tidak lepas dari gaya hidup, seperti menurunnya aktivitas fisik. Salah satu komplikasi yang dapat disebabkan oleh Obesitas adalah gangguan pendengaran, terutama gangguan pendengaran sensorineural yang disebabkan karena adanya kelainan mikroangiopati terutama pada telinga bagian dalam. Namun hubungan kejadian antara obsitas dengan gangguan pendengaran masih sering menjadi perdebatan, karena belum ada konsesus yang pasti. Tujuan penelitian untuk mengetahui hubungan obesitas dengan gangguan pendengaran sensorineural. Penelitian ini merupakan penelitian analitik dengan pendekatan cross-sectional, dengan data yang diperoleh dari pengukuran berat badan dan tinggi badan untuk melihat status indeks massa tubuhnya, selanjutnya akan dilakukan pemeriksaan fisik telinga, hidung, dan tenggorokan, dan pemeriksaan audiometri nada murni yang dilakukan terhadap 55 subjek. Teknik analisis data menggunakan statistik uji chi square hasil penelitian didapatkan hubungan antara obesitas dengan gangguan pendengaran sensorineural sebanyak 49,09\% dan derajat gangguan pendengaran terbanyak adaah derajat ringan sebanyak $27,07 \%$. Kesimpulan penelitian terdapat hubungan yang bermakna antara obesitas dengan gangguan pendengaran sensorineural.
\end{abstract}

\title{
Kata Kunci: Audiometri, Nada Murni, Obesitas
}

\begin{abstract}
Obesity is an increase in total body fat, that is if found to be overweight $>20 \%$ in men and $25 \%$ in women due to fat. Increased obesity cannot be separated from lifestyle, such as decreased physical activity. One complication that can be caused by obesity is hearing loss, especially sensorineural hearing loss caused by microangiopathic abnormalities, especially in the inner ear. But the relationship of events between obesity with hearing loss is still often a debate, because there is no definite consensus. The purpose of this research determine the relationship of obesity with sensorineural hearing loss. This research is an analytic study by obtaining crosssectional study, with data obtained from the assessment of body weight and height to see the status of the mass index, physical examination of the ear, and audiometric examination. Data analysis techniques using the chi square test statistics. Research result obtained relationship between obesity with sensorineural hearing loss as much as 49.09\% and the highest degree of hearing loss is mild degrees as much as 27.07\%. Research conclusions there is a significant relationship between obesity with sensorineural hearing loss.
\end{abstract}

Keyword: Hearing Loss, Obesity 


\section{PENDAHULUAN}

Obesitas merupakan kejadian peningkatan total lemak di dalam tubuh. Meningkatnya obesitas tidak lepas dari pola gaya hidup.(WHO, 2015) Secara global, total obesitas mengalami kenaikan sebesar $27,5 \%$ untuk dewasa dan $47,1 \%$ untuk anak-anak antara tahun 1980 dan 2013. (Dhanda \& Taheri, 2017) Penentuan Obesitas dapat dilakukan dengan mengukur indeks massa tubuh yang memperlihatkan berat badan dan tinggi badan $(\mathrm{Ng}$ et al., 2014).

Obesitas umumnya sering terjadi kebanyakan pada perempuan dibandingkan laki-laki. Selain itu pola aktivits fisik juga mempengaruh seseorang dikatakan obesitas. Orang gemuk lebih beresiko mengalami gangguan pendengaran sensorineural di bandingkan dengan berat badan yang normal (Abramovitch et al., 2019).Gangguan pendengaran jenis sensorineural terjadi karena adanya masalah di telinga dalam bisa juga disebabkan karena adanya masalah fungsi pada syaraf pendengaran. Salah satu yang menjadi penyebabnya adalah karena mengalami obesitas. Keadaan tuli sensorineural muncul bertahap.

Gangguan pendengaran sensorineural yang terjadi pada penderita obesitas disebabkan karena adanya kondisi terhambatnya aliran sehingga menyebabkan gangguan vasokonstriksi ke telinga bagian dalam. Telinga dalam memiliki sel-sel rambut yang berfungsi untuk mendeteksi suara yang masuk ke dalam telinga. Hal ini menyebabkan terhambatnya sel- sel rambut untuk menangkap suara. Karena itu, kurangnya aliran darah ke sterocilia dari sel - sel rambut bagian dalam di dalam koklea yang dihasilkan dari obesitas berkontribusi terhadap pendengaran.(Dhanda \& Taheri, 2017).

Dengan pemeriksaan audiometri dapat ditentukan ambang dengar penderita untuk mendapatkan informasi mengenai jenis dan derajat ketulian. Dari audiogram dapat dilihat apakah pendengaran normal atau tidak. Dengan pemeriksaan audiometri nada murni, diperoleh informasi mengenai ambang pendengaran pada frekuensi 125 $8000 \mathrm{~Hz}$. Walaupun frekuensi percakapan $(500-2000 \mathrm{~Hz})$ tercakup dalam pemeriksaan audiometri nada murni, pemeriksaan ini hanya memberikan sebagian gambaran mengenai kemampuan seseorang dalam mendengar. Sedangkan dengan pemeriksaan audiometri tutur dapat diperoleh informasi mengenai kemampuan penderita dalam memahami percakapan yang diperlukan dalam komunikasi dan interaksi antar manusia (Gelfand, 2001; Soetirto et al., 2001; Dhingra, 2008).

Audiometri nada murni adalah suatu 
alat elektronik yang menghasilkan bunyi yang relatif bebas bising ataupun energi suara pada kelebihan nada, karenanya disebut nada murni. Intensitas nada dapat dipertahankan pada tingkat tertentu, tidak seperti penala di mana intensitas nada segera berkurang setelah dibunyikan. Nada dapat pula diinterupsi sesuai kehendak, atau intensitas dapat dilemahkan pada interval tertentu dengan hambatan elektris dengan demikian intensitas bunyi dapat dihitung. Melalui pemeriksaan audiometri nada murni dapat dilihat batas ambang pendengaran dan hasil yang didapat juga akurat karena terdapat hasil yaitu melalui audiogram yang bisa dibaca berapa taraf pendengaran pada seseorang dalam beberapa frekuensi. (Liston \& Duvall 1997).

Hubungan antara obesitas dengan gangguan pendengaran sensorineural sampai saat ini masih menjadi perdebatan, karena masih belum ada konsensus yang pasti. Beberapa penelitian mengatakan bahwa terdapat hubungan antara obesitas dengan gangguan pendengaran sensorineural, seperti penelitian yang dilakukan oleh penelitian sebelumnya, yang menyatakan bahwa terjadi peningkatan insidensi gangguan pendengaran pada penderita obesitas, yang terjadi akibat dari kelainan di dalam vasokontriksi telinga dalam.(Kesuma \& Nasution, 2019)

https://doi.org/10.37362/jkph.v5i2.373
Selain itu menurut Teuku Husni dan Thursina dalam penelitiannya di Poliklinik THT- KL RSUD Dr.Zainoel Abidin Banda Aceh mendapatkan hasil dari 175 penderita gangguan pendengaran yang paling banyak terdapat pada kelompok umur 60-74 tahun (28\%), sebagian besar adalah laki-laki $(53,14 \%)$, bilateral $(80,57 \%)$ dan jenis ketulian berupa tuli sensorinueral $(49,43 \%)$. Pada kelompok tuli konduktif, derajat ketulian yang paling sering adalah bersifat sedang (31,82\%), kelompok tuli sensorinueral yaitu sedang dan sedang-berat $(23,7 \%)$, dan pada tuli campuran adalah derajat berat $(48,05)$. Presbikusis paling banyak dijumpai pada kelompok usia tua (60-74 tahun) 57,14\%, dan lebih sering pada laki-laki 52,38\%. Sedangkan kelompok usia 5-14 tahun merupakan kelompok usia yang paling sedikit mengalami gangguan pendengaran. (Husni \& Thursina ,2012).

Berdasarkan uraian diatas, maka peneliti tertarik untuk melakukan penelitian mengenai hubungan antara obesitas dengan gangguan pendengaran di RSU Haji, RS Putri Hijau Kota Medan dan di PT. Kasoem Hearing Head Office Medan, Sumatera Utara berdasarkan pemeriksaan audiometri nada murni. Peneliti ingin mengetahui apa saja jenis, derajat, dan usia pada penderita gangguan pendengaran.

\section{METODE}

https://doi.org/10.37362/jkph.v5i2.373 Jurnal Kesehatan Panrita Husada 
Penelitian ini merupakan penelitian analitik dengan pendekatan cross-sectional (potong lintang) yang dilakukan mulai dari bulan Desember 2019 hingga bulan Januari 2020 di RSU Haji, RS Putri Hijau Kota Medan dan di PT. Kasoem Hearing Head Office Medan, Sumatera Utara. Besar sampel ditentukan dengan menggunakan teknik non- probability sampling. Sampel yang digunakan sebanyak 55 orang.

Kriteria inklusi terdiri atas: jenis kelamin laki-laki atau perempuan, usia 18 59 tahun, tidak memiliki riwayat nyeri telinga, gangguan pendengaran yang dibawa sejak lahir, infeksi telinga, trauma kepala atau telinga, trauma akustik, penggunaan obat-obatan ototoksik seperti anti TBC/ kina/ golongan aminoglikosida. Apabila didapatkan pasien dengan usia > 59 tahun maka akan mempengaruhi hasil dalam Penelitian ini sudah mendapat persetujuan dari komisi etik penelitian kesehatan dari institusi kami dan informed consent dari semua subjek penelitian.

Tektik analisis data dilakukan dengan menggunakan SPSS versi 25.0. Penelitian ini menggunakan data primer yang diperoleh dari anamnesis, pemeriksaan fisik telinga, hidung, dan tenggorok, pemeriksaan dengan pemeriksaan audiometri nada murni pada semua subjek penelitian oleh pemeriksa di ruangan yang kedap suara.

\section{HASIL}

Hasil penelitian pada tabel 1 menunjukkan hubungan frekuensi subjek penelitian terhadap gangguan pendengaran pada pasien obesitas. Didapatkan pasien obesitas yang paling banyak adalah kelompok usia 40- 49 tahun sebanyak $40 \%$ dengan jenis kelamin terbanyak adalah perempuan $(50,90 \%)$.

Berdasarkan tabel 2 menunjukkan bahwa hubungan frekuensi jenis dan derajat gangguan pendengaran pada pasien obesitas di Rumah Sakit Umum Haji Kota Medan dan Rumah Sakit Putri Hijau Kota Medan. Didapatkan 27 orang $(49,09 \%)$ dengan derajat gangguan pendengaran terbanyak ialah derajat ringan sebanyak 15 orang $(27,7 \%)$.

Hasil penelitian pada tabel 3 menunjukkan adanya hubungan yang bermakna $(\mathrm{p}<0,05)$ antara obesitas yang tinggi dengan gangguan pendengaran. Dari perhitungan Prevalence Ratio diperolehnilai PR sebesar 4,767 atau PR $>1$, bermaknakan bahwa obesitas dapat menimbulkan terjadinya gangguan pendengaran sensorineural.

\section{PEMBAHASAN}

Pada penelitian ini, penderita obesitas lebih banyak terjadi pada perempuan dibandingkan laki - laki. Data 
ini tidak sesuai dengan penelitian yang dilakukan oleh peneliti sebelumnya bahwa, bahwa penelitian mereka menujukkan dari 61.052 subjek yang diteliti didapatkan penderita obesitas laki- laki 79,87\% dan perempuan 20,13\%. ${ }^{6}$ Namun, Penelitian ini sesuai dengan penelitian yang dilakukan oleh penelitian sebelumnya bahwa penelitian mereka menujukkan prevalensi terbanyak pasien obesitas $35 \%$ pada pria dan $40,4 \%$ pada wanita.(Flegal et al., 2016) Selanjutnya data penelitian ini sesuai dengan data dari WHO yang mengatakan bahwa Pada tahun 2014, 39\% dari orang dewasa berusia lebih dari18 tahun mengalami obesitas, dimana $30 \%$ pada laki - laki dan $40 \%$ pada perempuan.(Kim et al., 2016)

Penderita Obesitas lebih banyak terjadi pada laki - laki dibandingkan perempuan disebabkan karena gaya hidup yang tidak sehat (merokok, minum alkohol dan makan- makanan siap saji atau junk food, serta banyak konsumsi makanan berkalori dan tidak pernah berolahraga. Faktor utama yang paling berperan dalam obesitas pada pria adalah pola makan.(Flegal et al., 2016)

Pasien wanita lebih banyak obesitas dibandingkan laki-laki karena pola aktivitas yang kurang dibandingkan dengan laki-laki. Selain itu, pengaruh hormon leptin dalam meningkatkan rasa lapar dan diikuti dengan pengaruuh hormon estrogen dan juga hormon progesterone di dalam tubuh.

Sampel pada penelitian ini diambil mulai dari usia 18 tahun sampai usia 59 tahun, yang dibagi menjadi empat kelompok, yaitu kelompok usia 18-29 tahun, kelompok usia 30-39 tahun, kelompok usia 40-49 tahun, dan kelompok usia 50-59 tahun.

Hasil penelitian pada tabel 3 menunjukkan adanya hubungan yang bermakna $(\mathrm{p}<0,05)$ antara obesitas yang tinggi dengan gangguan pendengaran. Hal ini menunjukkan bahwa usia memberikan peranan terhadap kejadian gangguan pendengaran pada penderita obesitas. Hubungan ini menunjukkan bahwa semakin tinggi usia akan semakin meningkatkan risiko terjadinya gangguan pendengaran. Insiden gangguan pendengaran akan meningkat sejalan dengan usia.

Berdasarkan penelitian yang telah dilakukan kelompok yang terbanyak adalah pada usia 40-49 tahun, hal yang sama juga terlihat pada penelitian yang dilakukan oleh Pusat Kesehatan Columbia University mengatakan bahwa remaja $>18$ tahun lebih beresiko mengalami gangguan pendengaran di semua frekuensi yang dapat didengar manusia. Dikatakan bahwa obesitas dapat langsung atau tidak langsung menyebabkan gangguan pendengaran. Studi ini menganalisis data dari hampir 1.500 remaja 
dari National Health and

Nutrition

Examination.(Ng et al., 2014)

Tingginya angka kejadian pada usia 20-49 tahun disebabkan karena pada usia lebih dari 20 tahun mulai terjadi ketidakseimbangan dalam asupan energi atau kalori yang masuk dengan energi/kalori yang keluar, mereka sibuk bekerja dan malas untuk melakukan kegiatan yang mengurangi kalori seperti olahraga. Hal ini sesuai dengan pendapat penelitian sebelumnya yang menyatakan bahwa meningkatnya obesitas tak lepas dari gaya hidup, seperti menurunnya aktivitas fisik.

Faktor genetik juga menentukan mekanisme pengaturan berat badan melalui pengaruh hormon dan neural.(Limanan, 2013). Pada penelitian ini, memperlihatkan hasil distribusi frekuensi jenis gangguan pendengaran pada penderita obesitas dan non obesitas, dari tabel di atas dapat terlihat bahwa pada penderita obesitas, jenis gangguan pendengaran yang paling banyak adalah pada jenis gangguan pendengaran sensorineural.

Pada penelitian ini didapatkan derajat gangguan pendengaran pada penderita obesitas yang terbanyak adalah gangguan pendengaran derajat ringan kemudian disusul dengan derajat sedang dan yang terendah adalah gangguan pendengaran derajatberat.
Penelitian ini menyajikan hubungan penderita obesitas yang mengalami gangguan pendengaran sensorineural. Pada penelitian ini dari 29 orang penderita obesitas yang mengalami gangguan pendengara sensorineural, ditemukan bahwa penderita berjenis kelamin perempuan lebih banyak mengalami gangguan dibandingkan dengan laki-laki. Hal yang sama juga ditemukan pada penelitian sebelumnya, didapatkan bahwa penderita obesitas yang berjenis kelaminperempuan (17,9\%) mengalami gangguan pendengaran sensorineural lebih tinggi dibandingkan laki-laki sebanyak (11,5\%).(Kim et al., 2016)

Berdasarkan data juga diketahui bahwa kelompok usia tertinggi yang mengalami gangguan pendengaran adalah pada kelompok usia 20-39 tahun. Penelitian yang dilakukan oleh penelitian sebelumnya, menyatakan bahwa dengan bertambahnya usia dan kelebihan berat badan akan meningkatkan kemungkinan mengalami gangguan pendengaran yang lebih berat.

Sebuah penelitian terhadap remaja dan orang dewasa menemukan adanya hubungan antara obesitas dan ambang batas pendengaran yang lebih tinggi di semua frekuensi.(Rıfkı Üçler., n.d.)

Tingginya angka kejadian obesitas pada usia 30 tahun hingga lebih mulai terjadi saat peningkatan kadar asam lemak 
bebas dalam penggunaan dan penyimpanan glukosa. Ketika lemak tubuh meningkat, laju lipolisis akan meningkat, yang mengarah ke peningkatan mobilisasi kadar asam lemak dan akibatnya pada peningkatan oksidasi kadar asam lemak di otot dan hati. Penggunaan glukosa oleh otot akan menurun karena kada rasam lemak digunakan sebagai sumber energi alternatif, dan produksi glukosa hepatik meningkat sebagai respons terhadap oksidasi kadar asam lemak yang lebih tinggi. Hal ini menghasilkan hiperglikemia dan gangguan toleransi glukosa (Üçler et al., 2016)

Penelitian ini memperlihatkan distribusi frekuensi penderita obesitas dengan gangguan pendengaran sensiorineural lebih meningkat dibandingkan dengan pasien yang memiliki berat badan normal. Gangguan pendengaran pada pasien obesitas terjadi akibat adanya vasokontriksi yang terjadi di dalam telinga dalam yang menyebakan tidak mampunyai sel -sel rambut yang ada di dalam telinga dalam berdegenerasi dengan baik sehingga menyebabkan terjadinya penghambatan hantaran suara ke dalam telinga (Dhanda \& Taheri, 2017)

Klasifikasi dalam pemeriksaan audiometri nada murni sebagai berikut: pendengaran normal $(\leq 25$ dBHL $)$, gangguan pendengaran ringan (26-40 dBHL), gangguan pendengaran sedang (41-
$60 \mathrm{dBHL}$ ), gangguan pendengaran berat (61-80 dBHL), gangguan pendengaran sangat berat $(\geq 81 \mathrm{dBHL})$. Gangguan pendengaran sensorineural terjadi jika hantaran udara dan hantaran tulang $>25$ dB.(Ng et al., 2014)(Flegal et al., 2016)

Dari perhitungan Prevalence Ratio diperoleh nilai PR sebesar 4,767 atau PR>1, bermaknakan bahwa obesitas dapat menimbulkan terjadinya gangguan pendengaran sensorineural.

Banyaknya penderita Obesitas yang mengalami gangguan pendengaran jenis tuli sensorineural disebabkan karena terjadi mikroangiopati pada telinga bagian dalam terutama organ korti yang menimbulkan atrofi dan berkurangnya sel rambut.(Kim et al., 2016)

Gangguan pendengaran sensorineural akut terjadi pada perkiraan kejadian sekitar 5 hingga 20 per 100.000 orang per tahun. Insideninfarkarteri vertebrobasilar di mana pasien awalnya hadir dengan gangguan pendengaran sensorineural akuta dalah 1,21,4\%.(Ohki, 2013).

Pemeriksaan dengan menggunakan audiometer nada murni merupakan pemeriksaan rutin yang dilakukan untuk mendeteksi gangguan pendengaran. Dengan penelitian ini dapat diketahui faktor resiko obesitas terhadap gangguan pendengaran sehingga dapat dilakukan pemeriksaan 
audiometer secara berkala pada penderita obesitas untuk mendeteksi lebih awal gangguan dan mendapatkan penanganan yang lebih baik.

\section{KESIMPULAN DAN SARAN}

Pada hasil penelitian kami didapatkan gangguan pendengaran yang dialami penderita diabetes berdasarkan hasil pemeriksaan audiometri nada murni umumnya normal. Terdapat hubungan yang bermakna antara usia penderita obesitas terhadap gangguan pendengaran. Terdapat hubungan yang bermakna antara pemeriksaan audiometri nada murni pada penderita obesitas terhadap gangguan pendengaran. Terdapat hubungan yang bermakna $(\mathrm{p}<0,05)$ antara obesitas yang tinggi dengan gangguan pendengaran. kelompok usia tertinggi yang mengalami gangguan pendengaran adalah pada kelompok usia 20-39 tahun. Tingginya angka kejadian obesitas pada usia 30 tahun hingga lebih mulai terjadi saat peningkatan kadar asam lemak bebas dalam penggunaan dan penyimpanan glukosa.

Diperlukan Pengontrolan terhadap Status IMT yang berlebih untuk mencegah komplikasi, baik komplikasi pada gangguan pendengarannya dan juga komplikasi pada organ lainnya. kemudian diperlukan penelitian lanjutan dengan menggunakan pendekatan yang lebih tinggi seperti case control atau cohort untuk menentukan hubungan yang lebih pasti antara obesitas dengan gangguan pendengaran sensorineural.

Selain itu Perlunya penelitian longitudinal untuk melihat efek lanjut pada penderita obesitas yang terkontrol dan tidak terkontrol. Perlunya penelitian lebih lanjut dengan kontrol terhadap usia, penyakit lain, penyakit penyerta, dan komplikasi terhadap obesitas. Perlunya penanganan penyakit obesitas sejak dini untuk mencegah terjadinya komplikasi. Perlunya pemeriksaan audiometri yang berkala pada penderita obesitas. Perlunya pemakaian alat bantu dengar pada penderita obesitas yang mengalami gangguan pendengaran.

\section{DAFTAR PUSTAKA}

Abramovitch, A., Anholt, G. E., Cooperman, A., van Balkom, A. J. L. M., Giltay, E. J., Penninx, B. W., \& van Oppen, P. (2019). Body mass index in obsessive-compulsive disorder. Journal of Affective Disorders, 245, 145-151.

Dhanda, N., \& Taheri, S. (2017). A narrative review of obesity and hearing loss. International Journal of Obesity, 41(7), 1066-1073.

Dhingra P 2008.Anatomy of ear in diseases of ear, nose, and throat, India, Reed Elsevier India Private Limited. 
Flegal, K. M., Kruszon-Moran, D., Carroll, M. D., Fryar, C. D., \& Ogden, C. L. (2016). Trends in obesity among adults in the United States, 2005 to 2014. Jama, 315(21), 2284-2291.

Gelfand SA 2001.Essentials of audiology, New York, Thieme Medical Publisher.

Husni, T. H. T., \& Thursina, T. (2012). Pola Gangguan Pendengaran Di Poliklinik Telinga Hidung Tenggorok Kepala Leher (THT-KL) Rsud Dr. Zainoel Abidin Banda Aceh Berdasarkan Audiometri. Jurnal Kedokteran Syiah Kuala, 12(1), 16-22.

Kesuma, E., \& Nasution, M. E. S. (2019). RISK FACTORS ANALYSIS OF HEARING DISORDERS DUE TO NOISE ON MACHINERY WORKERS AT UNIVERSAL STEEL FACTORY. Buletin Farmatera, 4(2).

Kim, S. H., Won, Y. S., Kim, M. G., Baek, Y. J., Oh, I.-H., \& Yeo, S. G. (2016). Relationship between obesity and hearing loss. Acta Oto-Laryngologica, 136(10), 1046-1050.

Limanan, D. (2013). Hantaran sinyal leptin dan obesitas: Hubungannya dengan penyakit kardiovaskuler. EJournal Kedokteran Indonesia, 144-155.

Liston, S. L., \& Duvall, A. J. (1997). Embriologi, anatomi dan fisiologi telinga. Dalam: Adams GL, Boies LR, Higler PH, Ed. Buku ajar penyakit THT. Edisi ke-6. Jakarta: Penerbit Buku Kedokteran EGC, 27-38.

Ng, M., Fleming, T., Robinson, M., Thomson, B., Graetz, N., Margono, C., Mullany, E. C., Biryukov, S., Abbafati, C., \& Abera, S. F. (2014). Global, regional, and national prevalence of overweight and obesity in children and adults during 19802013: a systematic analysis for the Global Burden of Disease Study 2013. The Lancet, 384(9945), 766-781.

Ohki, M. (2013). Sensorineural hearing loss due to vertebrobasilar artery ischemiaillustrative case and literature review. J Neurol Neurophysiol S, 8.

Rıfkı Üçler. (n.d.). Email authorMahfuz TuranFatih GarçaÍsmail AcarMura. The association of obesity with hearing thresholds in women aged 1840 years.

Soetirto I, Hendarmin H \& Bashiruddin J 2001. Gangguan pendengaran dan kelainan telinga dalam Buku ajar ilmu kesehatan telinga hidung tenggorok kepala leher,Jakarta, Penerbit Fakultas Kedokteran Universitas Indonesia

Üçler, R., Turan, M., Garça, F., Acar, I., Atmaca, M., \& Cankaya, H. (2016). The association of obesity with 
hearing thresholds in women aged 18-

40 years. Endocrine, 52(1), 46-53.

WHO. (2015). Obesity: Preventing and Managing The Global Epidemic:

Technical Report Series. 
Tabel 1 . Hubungan Frekuensi Subjek Penelitian Berdasarkan Jenis Kelamin dan Usia

\begin{tabular}{lcc}
\hline \multicolumn{1}{c}{ Variable } & $\begin{array}{c}\text { Non Obesitas } \\
\mathbf{n}(\boldsymbol{\%})\end{array}$ & $\begin{array}{c}\text { Obesitas } \\
\mathbf{n}(\boldsymbol{\%})\end{array}$ \\
\hline Usia & $0(0)$ & $9(16,36)$ \\
$18-29$ tahun & $2(3,63)$ & $7(36,36)$ \\
$30-39$ tahun & & \\
& $5(9,09)$ & $22(40)$ \\
$40-49$ tahun & $1(1,8)$ & $9(16,36)$ \\
$50-59$ tahun & $7(12,72)$ & $19(34,54)$ \\
Jenis Kelamin & $1(1,8)$ & $28(50,90)$ \\
Laki-Laki & & \\
Perempuan & & \\
\hline
\end{tabular}

Tabel 2. Hubungan Fukueni Jenis dan Derajat Gangguan Pendengaran Pada Subjek Penelitian

\begin{tabular}{lcc}
\hline \multicolumn{1}{c}{ Variable } & $\begin{array}{c}\text { Non } \\
\text { Obesitas }\end{array}$ & Obesitas \\
\cline { 2 - 3 } & $\mathbf{n}(\%)$ & $\mathbf{n}(\%)$ \\
\hline Tuli Sensorineural & $7(12,72)$ & $19(34,54)$ \\
Tidak & $1(1,8)$ & $28(50,90)$ \\
Ya & $1(1,8)$ & $15(27,7)$ \\
Derajat Gangguan Pendengaran & 0 & $10(12,72)$ \\
Tuli Ringan & 0 & $2(3,63)$ \\
Tuli Sedang & 0 & 0 \\
Tuli Berat & 0 & \\
Tuli Sangat Berat & 0 & \\
\hline
\end{tabular}


Tabel 3. Hubungan Obesitas dengan Gangguan Pendengaran Sensorineural

\begin{tabular}{|c|c|c|c|c|c|c|c|}
\hline \multirow{3}{*}{$\begin{array}{l}\text { Kelompok } \\
\qquad(95 \% \mathrm{CI})\end{array}$} & \multicolumn{5}{|c|}{ Gangguan Pendengaran } & \multirow{3}{*}{$\mathbf{p}$} & \multirow{3}{*}{ Value $^{\mathrm{a}}$} \\
\hline & \multicolumn{2}{|r|}{$\mathbf{Y a}$} & & \multicolumn{2}{|c|}{ Tidak } & & \\
\hline & $\mathbf{N}$ & $\%$ & & $\mathbf{N}$ & $\%$ & & \\
\hline $\begin{array}{l}\text { Obesitas } \\
\text { Non Obesitas }\end{array}$ & $\begin{array}{l}2 \\
8\end{array}$ & $\begin{array}{l}\mathbf{5 0 , 9 0} \\
0,002^{b}\end{array}$ & 1 & 4,7 & & & \\
\hline
\end{tabular}

$$
\begin{aligned}
& \text { Ket }=\quad=\text { Berdasarkan uji Chi Square } \\
& \begin{array}{ll}
a \\
b
\end{array} \\
& P R=\text { Bermakna Secara Statistic } \\
& C I=\text { Confidence Interval }
\end{aligned}
$$

\begin{tabular}{|c|c|c|c|c|c|c|}
\hline \multirow{3}{*}{ Kelompok } & \multicolumn{4}{|c|}{$\begin{array}{c}\text { Gangguan Pendengaran } \\
\text { Sensorineural } \\
\end{array}$} & \multirow{3}{*}{ p Value ${ }^{a}$} & \multirow{3}{*}{$(95 \% \mathrm{CI})$} \\
\hline & \multicolumn{2}{|c|}{$\mathbf{Y a}$} & \multicolumn{2}{|c|}{ Tidak } & & \\
\hline & $\mathbf{N}$ & $\%$ & $\mathbf{N}$ & $\%$ & & \\
\hline \multirow[t]{2}{*}{ Obesitas } & 28 & 50,90 & 19 & 40,4 & & \\
\hline & & & & & & 4,767 \\
\hline Non Obesitas & 1 & 1,8 & 7 & 12,72 & $\mathbf{0 , 0 0 2 ^ { b }}$ & \\
\hline
\end{tabular}

Tabel 4. Hubungan Obesitas dengan Gangguan Pendengaran senseorineural

$$
\begin{array}{ll}
\begin{array}{ll}
\text { Ket } \\
a
\end{array} & =\text { Berdasarkan uji Chi Square } \\
b & =\text { Bermakna Secara Statistic } \\
P R & =\text { Prevalance Ratio } \\
C I & =\text { Confidence Interval }
\end{array}
$$

